Research Paper

\title{
Oxygen Supplementation Ameliorates Tibial Development via Stimulating Vascularization in Tibetan Chickens at High Altitudes
}

\author{
Shucheng Huang ${ }^{1}$, Xiaole Tong1, Mujeeb Ur Rehman¹, Meng Wang11, Lihong Zhang1, Lei Wang1, Jiakui \\ $\mathrm{Li}^{1,2}{ }^{\bowtie}$, Shijin Yang ${ }^{1 \bowtie}$ \\ 1. College of Veterinary Medicine, Huazhong Agricultural University, Wuhan 430070, People's Republic of China; \\ 2. College of Animals Husbandry and Veterinary Medicine, Tibet Agricultural and Animal Husbandry University, Nyingchi 860000 Tibet, People's Republic \\ of China. \\ $\square$ Corresponding authors: Jiakui Li, College of Animal husbandry and Veterinary Medicine, Tibet Agricultural and Animal Husbandry University, Nyingchi \\ 860000, Tibet, China. Telephone: +86-027-87286251. E-mail: lijk210@sina.com; Shijin Yang, College of Veterinary Medicine, Huazhong Agricultural University, \\ Wuhan 430070, People's Republic of China. E-mail: 979329262@qq.com. \\ (c) Ivyspring International Publisher. This is an open access article distributed under the terms of the Creative Commons Attribution (CC BY-NC) license \\ (https://creativecommons.org/licenses/by-nc/4.0/). See http://ivyspring.com/terms for full terms and conditions.
}

Received: 2017.09.04; Accepted: 2017.10.15; Published: 2017.11.27

\begin{abstract}
Tibetan chickens (TBCs) living in high-altitude hypoxic environment, are characterized by delayed growth and small size as compared to low-altitude broiler chickens. Increasing evidences signify the beneficial effect of oxygen $\left(\mathrm{O}_{2}\right)$ supplementation in animal's body for regulating their body growth and organ development. However, it is still unclear that whether $\mathrm{O}_{2}$ supplementation has an ameliorative and protective role in TBCs living at high altitude. In this study, we first found that $\mathrm{O}_{2}$ supplementation not only increased the survival rate but also promoted the growth of TBCs associated with bone development. Importantly, we observed that the increase of vascular distribution in the tibial hypertrophic zone could contribute to promote growth and development of the tibia, which is highly correlated with the up-regulated expression level of vascular endothelial growth factor (VEGF)-A and VEGF receptor-1 (VEGFR1). Additionally, hypoxia inducible factor (HIF)-la also has a stimulative elevation by $\mathrm{O}_{2}$ supplementation. These results were confirmed by histology, immunohistochemistry, qRT-PCR and Western blotting techniques. Altogether, these findings demonstrated that the up-regulation of VEGFA and its receptors are accompanied by proangiogeneic factor (HIF-l $\alpha$ ) expression, which were required for angiogenesis to meliorate tibia development of TBCs in hypoxia-induced bone suppression that occurred during $\mathrm{O}_{2}$ supplementation. Thus, $\mathrm{O}_{2}$ supplementation may serve as a good applicant for promoting and meliorating bone development in juvenile high-altitude animals.
\end{abstract}

Key words: angiogenesis, bone development, oxygen supplementation, VEGFA, Tibetan chicken.

\section{Introduction}

Tibetan chickens (TBCs) are an aboriginal breed of the high-altitude hypoxic environment of Tibetan plateau $(2,600 \quad \mathrm{~m} \sim 4,500 \mathrm{~m}$ above sea level $)$ characterized by slow growth and small size. This breed has inhabited the Tibetan plateau approximately 1,000 years and now it has fully adapted to the local rigorous environmental condition [1-3]. Previous studies indicated that oxygen $\left(\mathrm{O}_{2}\right)$ inadequate supply could compromise physiological performance, biological functions and growth capacity of animals [4, 5]. Moreover, González-Muniesa et al. found that normobaric hypoxia reduced food intake of rats resulting in weight loss [6]. Similar results were also observed in rats raised at plateau of high altitude [7]. Therefore, these characteristics of TBCs may be closely related to the local hypoxic environment [3].

Numerous studies have been found that $\mathrm{O}_{2}$ 
supplementation as a treatment has some beneficial effects for several diseases, such as chronic cardiopulmonary disease, diabetes and ischemia wounds [8-11]. Although increased $\mathrm{O}_{2}$ supply has already been demonstrated that it has beneficial effects including improve action on tissue oxygenation via increased the amount of dissolved $\mathrm{O}_{2}$ in blood, promote angiogenesis and improve wound healing $[12,13]$. However, its specific role(s) in the growth and development of TBCs and the underlying physiological mechanisms are unclear. Sgavioli et al. reported that the leg problems of broilers mainly caused by abnormal bone development have a direct relationship with the increase in weight gain, which simultaneously means that the development of bones may largely affect the growth of broiler chickens [14]. Therefore, the changes of bone development after hyperoxia treatment deserve to be established. In addition, Sheikh et al. have already demonstrated that increasing $\mathrm{O}_{2}$ contents in hypoxic and/or ischemic wounds could accelerate the healing process through increasing blood vessels growth [15]. Moreover, the development of bone depends on the blood vessels act as important tissue structures that deliver oxygen and nutritions [16]. Based on the above mentioned, although the development of blood vessels is very important for the growth of bone, the specific roles of $\mathrm{O}_{2}$ supplementation in vascular growth to promote bone development is less well understood $[17,18]$.

Brinkmann et al. indicated that alternating hypoxia/hyperoxia may induce a more reliable pro-angiogenic regulators up-regulation compared with normoxia [11]. Furthermore, several studies have been reported that high oxygen concentrations can modulate mRNA expression of several genes and related protein secretion including hypoxia inducible factor (HIF)-1a (a master oxygen sensitive transcriptional regulator), vascular endothelial growth factor-A (VEGFA), and interleukin (IL)-8 [15, 19-21]. Particularly VEGFA, VEGF receptor-1 (VEGFR1/Flt-1) and VEGFR2 (KDR/Flk-1) are the critical pro-angiogenic factor for vascular formation $[11,22,23]$. Kendall et al. reported that Sprague-Dawley rats exposed to $100 \% \mathrm{O}_{2}$ increased the VEGF synthesis in wounds [24]. Thus, high oxygen concentrations may play a potential role in angiogenesis-related genes up-regulation to promote the vascular formation. Although vascular formation in the tibia growth plates has been shown to be essential for bone development, the underlying molecular mechanisms of angiogenesis in bone development are also not fully understood [25, 26]. Here, we observed that HIF-1a activity was also activated under the $\mathrm{O}_{2}$ supplementation conditions. In addition, activation of VEGFA and its receptors in bone stimulates the growth and development of blood vessels to promote the bone development. Our findings revealed that the activation of angiogenesis-related genes by $\mathrm{O}_{2}$ supplementation is involved in bone development that contribute to the growth of TBCs and ameliorate negative effects on TBCs due to long-term living in high-altitude hypoxic environment.

\section{Materials and Methods}

\section{Experimental animal}

One-day old healthy TBCs $(n=120)$ were purchased from a commercial hatchery at Lhasa, China and shifted to the laboratory of Tibet Agricultural and Animal Husbandry College (nearly $3,000 \mathrm{~m}$ above sea level, $17 \% \mathrm{O}_{2}$ content) on the same day. The chicks were raised in two layer metal cages (size, $80 \mathrm{~cm} \times 60 \mathrm{~cm} \times 50 \mathrm{~cm}$ ) for 14 days. The brooding temperature was maintained from $33^{\circ} \mathrm{C}$ to $35^{\circ} \mathrm{C}$ during the first week and steadily reduced up to $29^{\circ} \mathrm{C}$ at the end of second week. Daily lighting was fixed as $23 \mathrm{~h}$ for light and $1 \mathrm{~h}$ for dark during the experiment period. Additionally, feed and water were provided ad libitum.

The study was performed under the instructions and approval of Laboratory Animal Research Centre of Hubei province in China and the Animal Welfare and Ethics Committee of the Huazhong Agricultural University (Permit No. 4200695757).

\section{$\mathbf{O}_{2}$ supplementation management}

As shown in Fig. 1, all the chicks were randomly assigned to two groups: oxygen supplementation group (OSG) with an approximately $21 \% \mathrm{O}_{2}$ content (namely hypobaric normoxia condition) and natural hypoxia group (NHG, $17 \% \mathrm{O}_{2}$ content). In each group, 60 chicks were equally divided into 4 replicates, Furthermore, all the relevant indicators were examined at day $3,-7,-10$ and -14 of the trial, respectively. During the experiment, OSG was maintained by using oxygenerator (Yuwell, Suzhou, China). Moreover, the $\mathrm{O}_{2}$ content of the OSG and NHG was monitored by a gas detector (CY-7B, Oxygen Analysis Instrument Factory, Jiande, China) during the experiment.

\section{Production performance analysis}

The chicks with the cage were group-weighed at each preset point of time as each repeating group weight, and experimental chick was recorded individually as a body weight (BW). At the same time, average daily weight gain (ADG) and average daily feed intake (ADFI) were calculated and recorded according to each group weighted. In addition, feed 
consumption (FC) was also determined and FC per chick (g/chick) was calculated by dividing the total FC of each cage by the actual number of chicks in that cage at different experimental point. The feed conversion ratio $(\mathrm{FCR})$ was determined as the FC per body weight gain $(\mathrm{g} / \mathrm{g})$ per cage per time. Moreover, mortality of TBC (no breathing and no heartbeat) was also recorded timely as it occurred.

\section{Tibial growth plate collection}

Eight chicks from both NHG and OSG were randomly chosen for further examination at day $3,-7$, -10 and -14 of the experiment (Fig. 1). All the group chickens were euthanized by cervical dislocation before injection of pentobarbital $(25 \mathrm{mg} / \mathrm{kg})$ was used. The tibia was retrieved and growth plate were detached from articular cartilage of the tibia via surgical knife and instantly frozen in liquid nitrogen as previously described [3,27].

\section{Measurement of tibial parameters}

All chicks were sacrificed, then tibia samples $(n=16)$ were collected for tibia weight (T. weight, $\mathrm{mg})$, tibia Length (T. length, $\mathrm{mm}$ ), and tibia mid-diameter (T. mid-diameter, $\mathrm{mm}$ ). These parameters were determined by an electronic balance sensitive to 0.001 $\mathrm{g}$ and Digital Calipers (\#SATA91511, TATA Company, Shanghai, China), respectively. In addition, tibia weight index ( $T$. weight index, was determined as the T. weight per BW for each bird, $\mathrm{mg} / \mathrm{g}$ ) was calculated.

\section{Histology of the tibial growth plates}

As previously described the stripping of the tibial longitudinal muscles and preparation of sagittal sections of the proximal tibial growth plates were performed to analyze the morphology [3, 27]. Collected tibial bone samples $(\mathrm{n}=3)$ were fixed in $4 \%$ paraformaldehyde at $4^{\circ} \mathrm{C}$ in PBS and decalcified in $10 \%$ EDTA. After the samples were dehydrated in ethanol and cleared in xylene, all the samples were embedded in paraffin, and histological sections of $4 \sim 5$ $\mu \mathrm{m}$ thickness were prepared and stained with hematoxylin and eosin (H\&E) for microscopic examination as previously described [26, 28]. In addition, the area of blood vessel and number of blood vessels in the hypertrophic zone adjacent to the tibial growth plate (3 chicks/group, three different microscopic fields/chick) were counted with two isolated groups using Image-Pro® Plus 6.0. $[29,30]$.

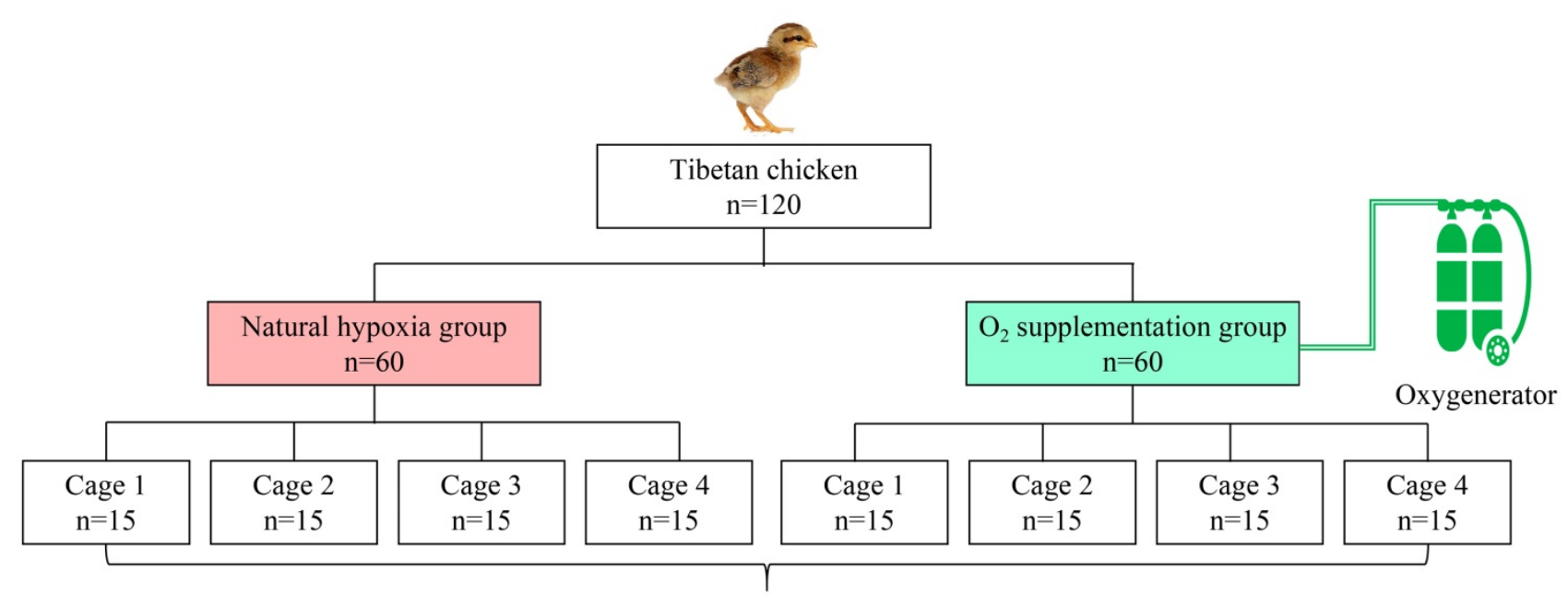

At each experimental point, two chicks were randomly chosen from each cage.

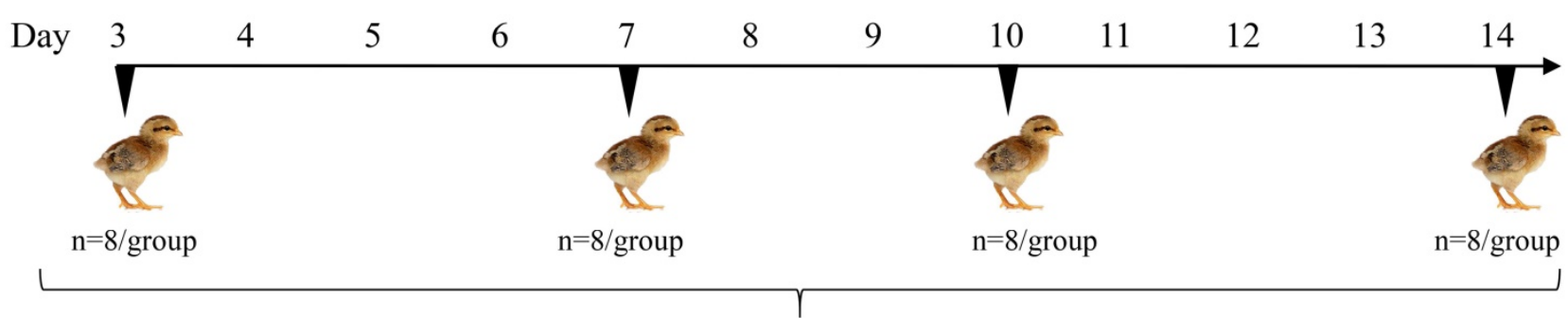

Samples collected for analysis

Figure 1. Flow diagram of the progress through different steps of the trial used in current study. 


\section{Immunohistochemical analysis}

Decalcified tissues of tibia were embedded in paraffin and sectioned into $4 \sim 5 \mu \mathrm{m}$ slices. After the sections were deparaffinizedin xylene and rehydrated using a graded alcohol series, the sections were incubated in $3 \% \mathrm{H}_{2} \mathrm{O}_{2}$ for $10 \mathrm{~min}$ and placed in $0.1 \%$ trypsin at $37^{\circ} \mathrm{C}$ for $30 \mathrm{~min}$ for antigen retrieval. The sections were then incubated with primary antibody against HIF-1a and VEGFA (\#A11945 and \#A5708, respectively; ABclonal technology). Next, the sections were reacted with HRP labeled rabbit anti-goat secondary antibodies (DAKO, Beijing, China, \#K5007) for $30 \mathrm{~min}$ at $37^{\circ} \mathrm{C}$. The sections were then stained with 3, 3-diaminobenzidine (DAB) kit (DAKO, Beijing, China, \#K5007) and finally counterstained with hematoxylin. The specimens $(n=3)$ were examined using a Nikon image analyzer (NIKON ECLIPSE 80i), and Image-Pro ${ }^{\circledR}$ Plus 6.0 software as a professional software for pathological image manipulation was used to quantitate the number of immunohistochemical staining [29].

\section{RNA extraction and reverse transcription}

Total RNA was removed from each sample of roughly $100 \mathrm{mg}$ of primary tibial growth plate cartilage, collected from each group using the TRIzol reagent (Life Technologies, Carlsbad, California, USA). cDNA was produced via EasyScript One-Step gDNA Removal and cDNA Synthesis Kit (TransBionovo Co., Ltd, Beijing, China) as per instructions of the manufactures. Reverse transcription was done by using a reaction temperatures of $42{ }^{\circ} \mathrm{C} / 15 \mathrm{~min}$ and $85{ }^{\circ} \mathrm{C} / 5 \mathrm{sec}$ in applied thermocycler (Biosystems CA, USA). cDNA was synthesized in a total volume of $25 \mathrm{ul}$ reaction mixture containing oligo $(\mathrm{dt})^{18}$, $2 \times \mathrm{ES}$ Reaction Mix, gDNA Remover, RT Enzyme Mix and 2,000 ng RNA. Finally, the target genes were identified via agarose gel.

\section{Quantitative Real-Time PCR (qRT- PCR)}

Specific primers set was designed and synthesized according to the Gallus gallus published sequences (Table 1), qRT-PCR was performed with

Table 1. Primers used for qRT-PCR analysis

\begin{tabular}{llll}
\hline Gene & Primer Sequence $\left(5^{\prime}-3^{\prime}\right)$ & Amplicon size & Genbank \\
\hline GAPDH & $\begin{array}{l}\text { Forward: CCTCTCTGGCAAAGTCCAAG } \\
\text { Reverse: GGTCACGCTCCTGGAAGATA }\end{array}$ & $176 \mathrm{bp}$ & NM_204305.1 \\
HIF-1a & $\begin{array}{l}\text { Forward: TGAGAGAAATGCTTACACACAG } \\
\text { Reverse: TGATGGGTGAGGAATTGGTTCAC }\end{array}$ & $263 \mathrm{bp}$ & XM_015287266.1 \\
\multirow{2}{*}{ VEGFA } & $\begin{array}{l}\text { Forward: CGATGAGGGCCTAGAATGTGTC } \\
\text { Reverse: AGCTCATGTGCGCTATGTGC }\end{array}$ & $101 \mathrm{bp}$ & NM_205042.2 \\
\multirow{2}{*}{ VEGFR1 } & $\begin{array}{l}\text { Forward: TGTAACTAAGTATGCCTGTGG } \\
\text { Reverse: GGAGTTGTTGGGTATCTGC }\end{array}$ & $114 \mathrm{bp}$ & NM_204252.1 \\
& & & \\
\hline
\end{tabular}

TransStart Tip Green qPCR Kit (TransBionovo Co., Ltd, Beijing, China) in Step One-Plus ${ }^{\mathrm{TM}}$ Real-Time PCR System (Applied Biosystems, CA, USA). The procedure was as follow: 1 cycle of $30 \mathrm{sec}$ at $94^{\circ} \mathrm{C}$, and 45 amplification cycles of $5 \mathrm{sec}$ at $94^{\circ} \mathrm{C}$ and $30 \mathrm{sec}$ at 58 $\sim 60^{\circ} \mathrm{C}$, of dissociation stage. All reactions were performed in triplicate. GAPDH was used as the internal control, and the relative expression of each target gene normalized by the expression of GAPDH was calculated by the $\Delta \mathrm{Ct}$ method.

\section{Western blotting analysis}

Tibia growth plates were homogenized in ice-cold buffer and incubated at $4^{\circ} \mathrm{C}$ for 2 hours. The samples were centrifuged at $12,000 \mathrm{rpm}$ for $10 \mathrm{~min}$ to collect the supernatant (total protein) and their concentrations were determined using BCA protein quantitative detection kit (Servicebio technology, Wuhan, China) and then all samples were cryo-preserved at $-70{ }^{\circ} \mathrm{C}$ for subsequent use. Protein samples were separated by SDS-PAGE on $12 \%$ polyacrylamide gel until the dye band reached the end of the gel and were then transferred to PVDF membranes, which were incubated in 5\% skimmed milk at room temperature for 1 hour. The membranes were incubated overnight at $4^{\circ} \mathrm{C}$ with rabbit monoclonal anti-HIF-1a, anti-VEGFA and anti-VEGFR1 primary antibodies (ABclonal technology, \#A11945, \#A5708 and \#A1277, respectively, 1:1,000) and then were incubated with secondary antibody (1:3,000 dilution) (HRP labeled rabbit anti-goat secondary antibodies) for 1 hour at room temperature. After washing, the bands were visualized and exposed by Chemiluminescence and radiography film, respectively. The images were taken using an imaging system (EPSON, China, \#V300).

\section{Enzyme-linked immunosorbent assay (ELISA)}

All blood samples were centrifuged at 3,500 rpm for $10 \mathrm{~min}$, and the supernatants were stored at $-80^{\circ} \mathrm{C}$ until use. The serum levels of HIF-1a(Elisa Lab, \#JYM0131Ch, ColorfulGene Biological Technology), VEGFA (Biofine, \#E75113, Equation Jiahong Technology), VEGFR2 (Biofine, \#E75148, Equation Jiahong Technology), and IL-8 (Biofine, \#E75019, Equation Jiahong Technology) for each group were measured using a chicken-specific ELISA kit according to manufacturer's instructions. The optical density values of each well were determined within 15 min at a wavelength of $450 \mathrm{~nm}$ using a Thermo Scientific Microplate Reader. Each experiment was performed at least 
three times.
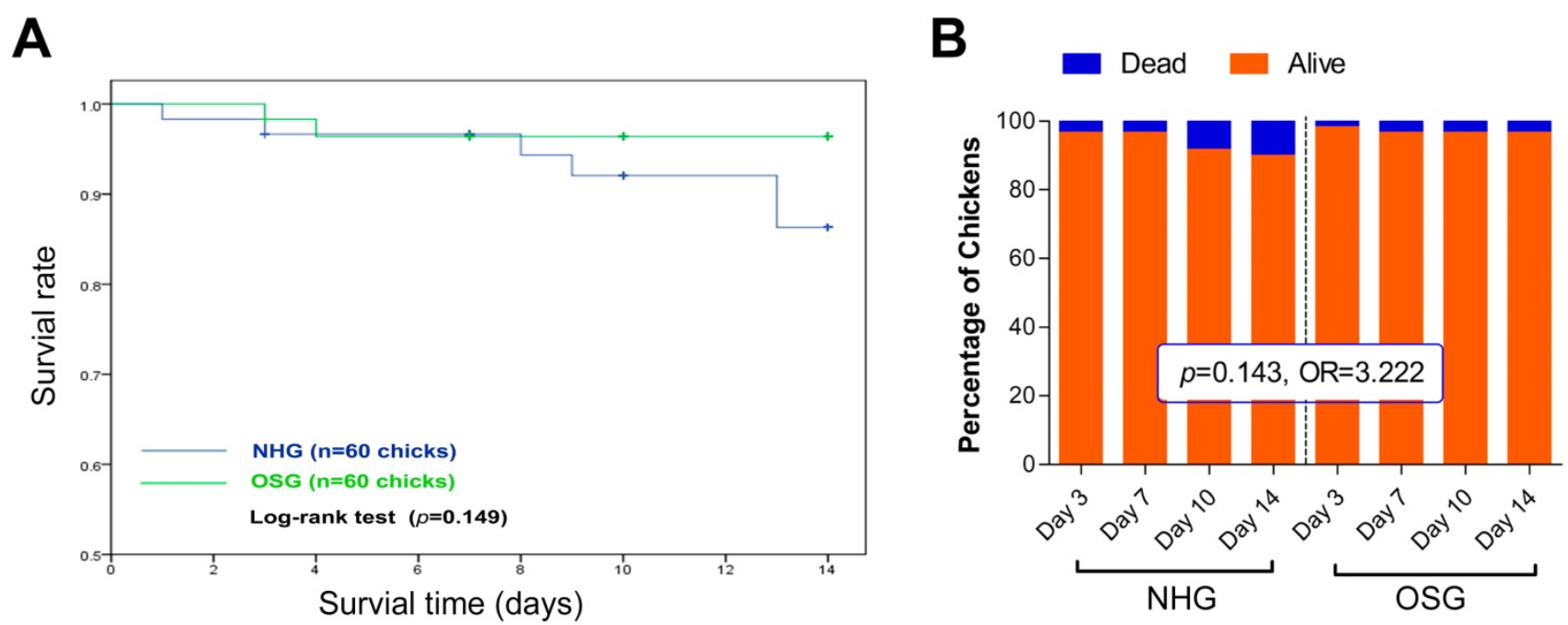

Figure 2. Effects of $\mathrm{O}_{2}$ supplementation on the survival rate of Tibetan chickens reared at high altitude. (A) Kaplan-Meier survival curve was used to analyse the survival rate of TBCs in the OSG and NHG, and the log-rank test was used to estimate differences in two groups. The survival rate of the OSG was increased by $10.1 \%$ on day 14 compared with the NHG. (B) The number of deaths of Tibetan chicken per day was recorded, then was analyzed using chi-square $\left(X^{2}\right)$. OR: Odds ratio; $95 \% \mathrm{Cl}$ : 95\% confidence interval; NHG: natural hypoxia group; OSG: oxygen supplementation group.

\section{Statistical analysis}

All analyses were performed to evaluate comparison analyses of two groups using the $x^{2}$ test and student's $t$ - test via SPSS Statistics software (SPSS Version 17.0. Chicago, IL), unless otherwise specified. The Kaplan-Meier method was used to analyse survival rate, and the log-rank test was used to estimate differences in survival of TBCs [31]. P-values less than 0.05 were considered statistically significant and the values were presented as means \pm SD.

\section{Results}

\section{$\mathrm{O}_{2}$ supplementation improves survival rate of the Tibetan chicken}

To investigate the effect of $\mathrm{O}_{2}$ supplementation on high-altitude TBCs, we initially recorded its mortality. As shown in Fig. 2B, the rate of mortality in the NHG and OSG was 10\% (6/60) and 3.33\% (2/60), respectively, throughout the experiment (from day 1 to day 14). Although, no significant difference of mortality was observed in these two groups and the survival rate of TBCs in OSG $(96.4 \%)$ was higher than that of NHG $(86.3 \%)$ during the whole experiment (Fig. 2A). Additionally, chi-square analysis showed that TBCs in the OSG have a nearly 3.2 fold higher anti-mortality risk than the NHG (OR=3.222, 95\% $\mathrm{CI}=0.62 \sim 16.66$; Fig. 2B). It is worth noting that TBCs living in high-altitude hypoxic environment for thousands of years, therefore $21 \% \mathrm{O}_{2}$ content is a hypobaric hyperoxia condition for them [2]. While these results showed that increasing the amount of $\mathrm{O}_{2}$ in the inhaled air can diminish the mortality rate of
TBCs.

\section{$\mathrm{O}_{2}$ supplementation elevates overall performance of the Tibetan chicken}

TBCs are high-altitude poultry breed of delayed growing and small size, which may be related to their livability in long-term hypoxic environment [3]. In this study, the BW was significantly difference $(p=0.015)$ in the NHG and OSG and only reached $55.54 \pm 10.26 \mathrm{~g}$ and $67.44 \pm 6.38 \mathrm{~g}$, respectively at day 14 (Fig. 3A). As shown in Fig. 3B, there was no significant difference in the average daily feed intake (ADFI) of TBCs in the two groups, except on day 14 $(p=0.002)$. However, the average daily weight gain (ADG) was significantly increased on day 10 and -14 ( $p=0.022$ and $p=0.004$, respectively) and the feed conversion ratio (FCR) was decreased on day 10 and $-14(p=0.005$ and $p=0.014$, respectively) in the OSG (Fig. 3C and D). These evidences strongly suggest that $\mathrm{O}_{2}$ supplementation could enhance the feed intake and can promote the growth of TBCs.

\section{$\mathrm{O}_{2}$ supplementation promotes tibia growth of Tibetan chickens}

Interestingly, statistical analysis showed that there was a significant correlation $(r=0.935, p<0.001)$ between the changes in BW and T. weight of chickens as shown in Fig. 4B. To examine the changes of tibia parameters in TBCs, we performed $\mathrm{T}$. weight weighing, $T$. length and $T$. mid-diameter measurement obtained from two experimental groups at the age of day $3,-7,-10$ and -14 (Fig 4A, Fig 4C-F). T. weight of the OSG was markedly increased at the age of day 10 and -14 ( $p=0.019$ and $p=0.006$, respectively) 
compared to the NHG. However, the T. weight index (T. weight/BW, mg/g) no significant change, except at age of day $7(p<0.001)$ between the two groups. Additionally, the T. length continued to grow during the experimental period and $\mathrm{O}_{2}$ supplementation group had a more obvious increase than NHG on day $14(p=0.03)$. Similarity, the T. mid-diameter of OSG was also elevated on day 7 and $-14 \quad(p=0.011$ and $p=0.01$, respectively).

Additionally, a heat-map clearly showing the changes in tibia parameters of the experimental groups are presented in Fig. 4G. The BW, T. weight, T. length, and T. mid-diameter were increased in OSG during the experiment, particularly on day 10 and -14 . However, T. weight index showed the different changes on day 14, which suggests that the BW of the Tibetan chicken has a faster growth than tibia in the $\mathrm{O}_{2}$ supplementation conditions. These results collectively demonstrated that $\mathrm{O}_{2}$ supplementation not only enhances the growth rate of TBCs, but also meliorates its bone development.

\section{Vascular distribution was increased in the zone of tibial hypertrophy}

It is well known that the growth and

A

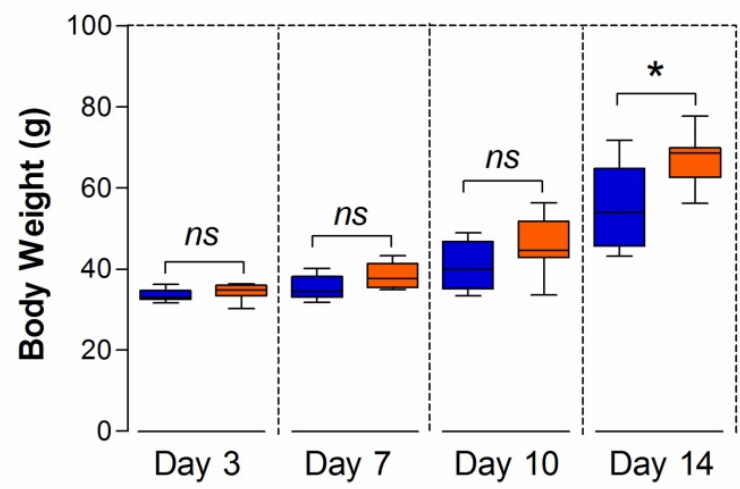

C

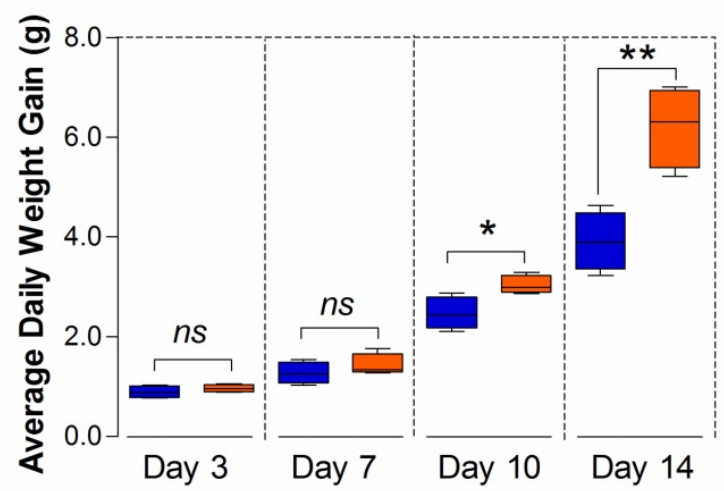

development of the bone cannot be separated from the nutritional support of blood [16]. Therefore, we next checked whether the development of the tibia is correlated with vascular distribution in the tibial growth plates. In this study, histological assessments showed that the vascular distribution slightly increased after two weeks of $\mathrm{O}_{2}$ supplementation when compared with the NHG, as shown in Fig. 5A. Simultaneously, the statistical data showed that the relative area of blood vessels was increased on day 10 and -14 ( $p=0.032$ and $p=0.006$, respectively), and the number of blood vessels were also increased on day 3 and -7 ( $p=0.043$ and $p=0.002$, respectively), except on day $10(p=0.018)$, in the OSG as the histological pictures are shown in Fig. 5B and C. In addition, the area of blood vessels was strongly correlated with $\mathrm{T}$. weight $(r=0.546, p=0.006)$, T. length $(r=0.742, p<0.001)$, and T. mid-diameter $(r=0.572, p=0.003)$ as shown in Fig. 5D-F. Hence, these observations demonstrated that tibial vascular distribution was enhanced under $\mathrm{O}_{2}$ supplementation conditions associated with tibial mass and tibial volume.

B

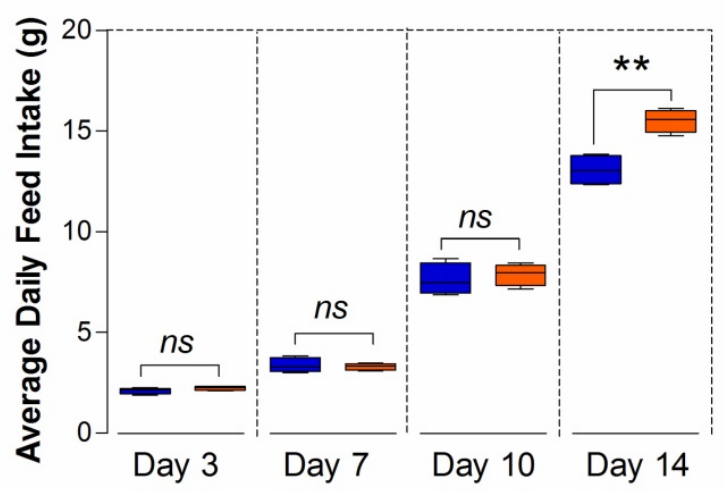

D

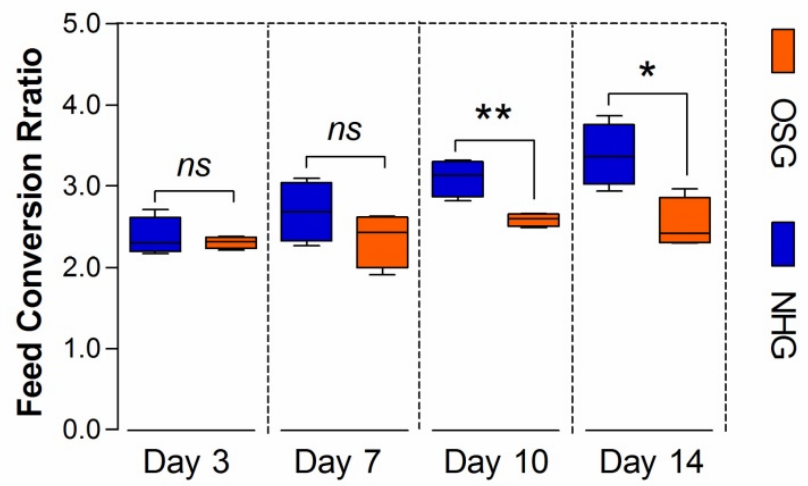

Figure 3. $\mathrm{O}_{2}$ supplementation elevated the overall performance of Tibetan chickens. (A-D) The body weight, average daily feed intake, and average daily weight gain of TBC in the OSG were obviously increased, especially on day 14. At the same time, the feed conversion ratio had a lower value than NHG. The data 
are expressed as the mean \pm SD. Student's $t$ test, ${ }^{*} p<0.05,{ }^{* *} p<0.01, n=4$ cages for each group; ns: not significant; NHG: natural hypoxia group; OSG: oxygen supplementation group.

\section{A}

B

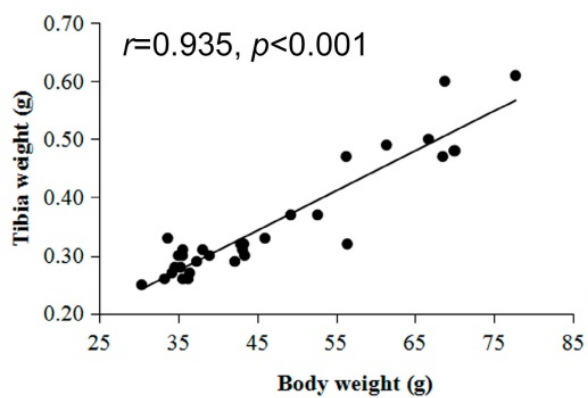

C

D

T. Length

E

$\mathbf{F}$

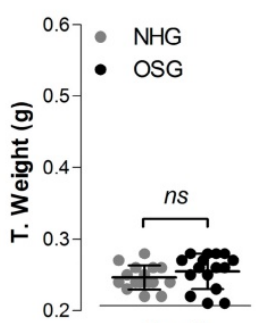

Day 3

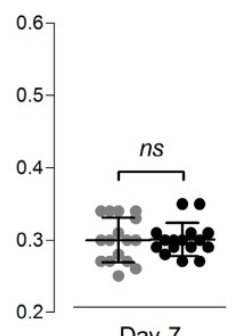

Day 7

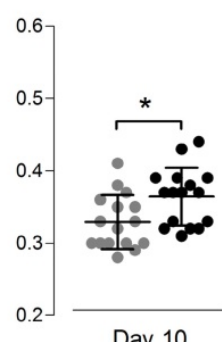

Day 10

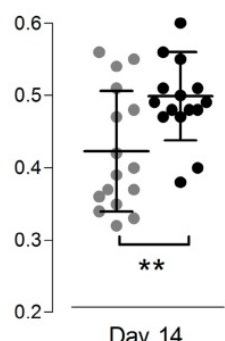

Day 14
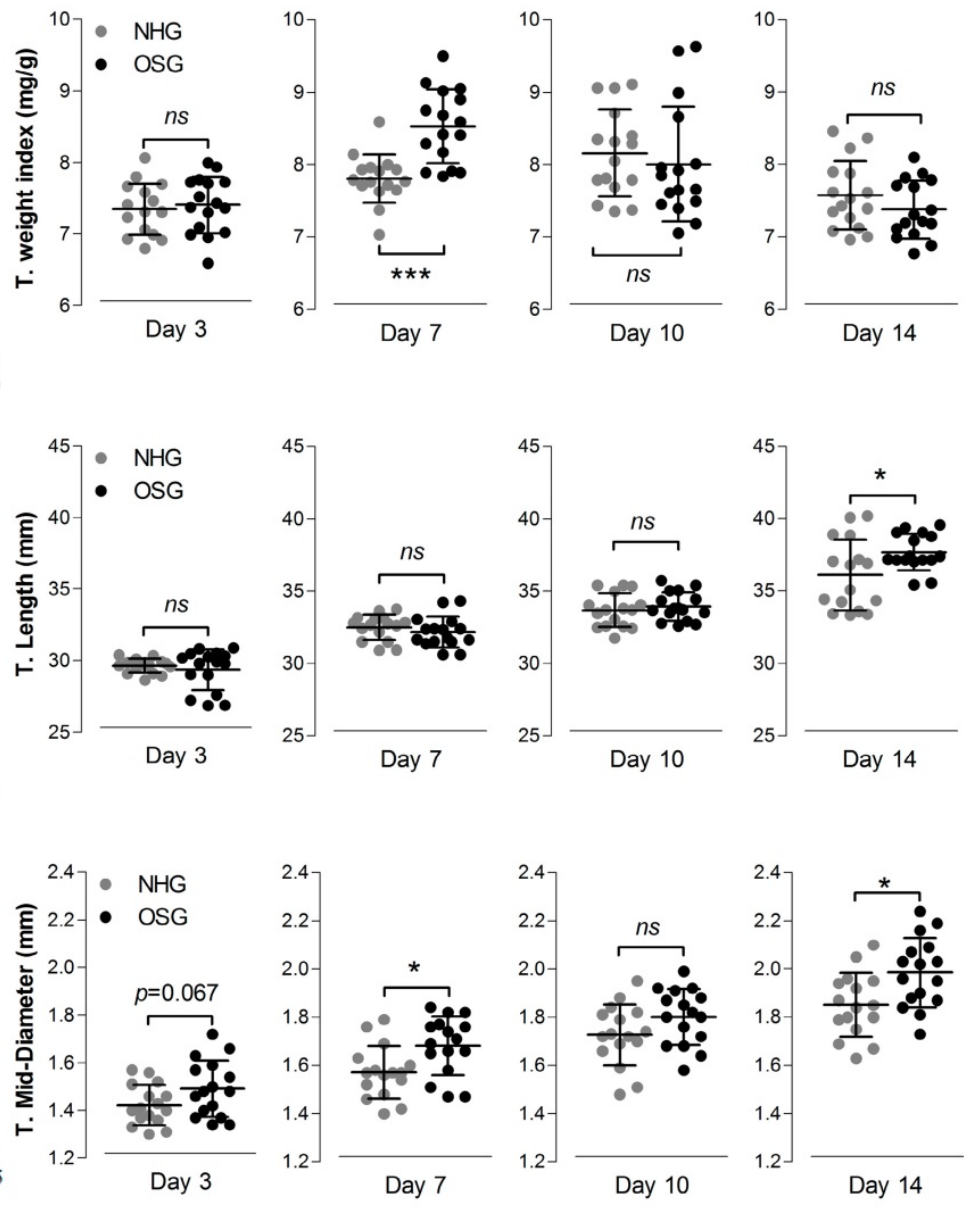

\section{G}

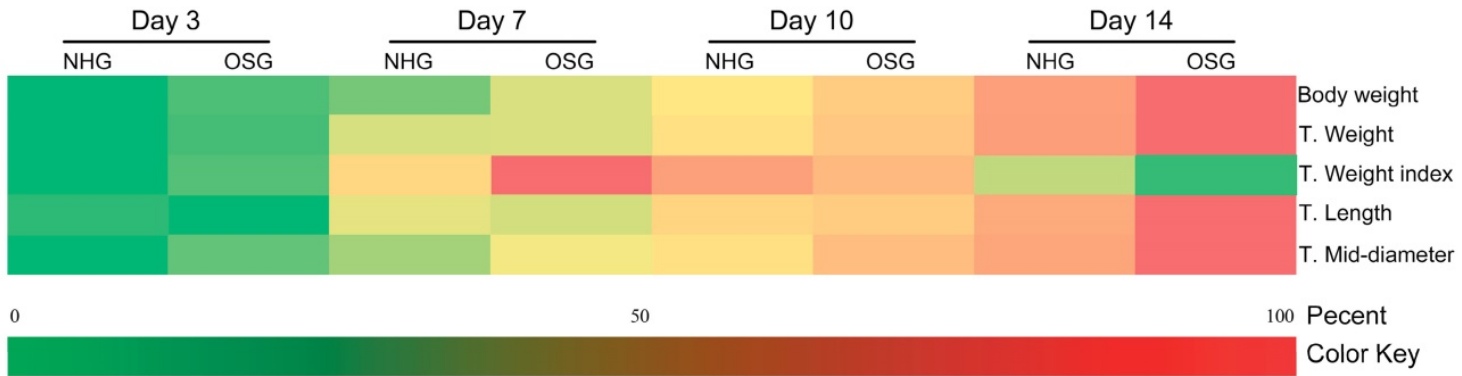

Figure 4. $\mathrm{O}_{2}$ supplementation increased the tibia parameters of Tibetan chickens. (A) Standard for the measurement of T. length (tibia length) and T. mid-diameter (tibia mid-diameter). (B) Correlation analysis of BW and T. weight during the experiment with Pearson test. (C-F) The weight, length, and mid-diameter of the tibia were record 
and the tibia weight index (T. weight index) was determined as the tibia weight per body weight (T. weight/BW, mg/g) between OSG and NHG. (g) The change of tibial parameters were shown in heat map using the indicated pseudo color scale from percent 0 (green) to percent 100 (red) relative to average values. The data are presented as the mean \pm SD. Student's $t$ test, " $p<0.05,{ }^{* * * *} p<0.001, n=16$ tibia samples; ns: not significant; NHG: natural hypoxia group; OSG: oxygen supplementation group.

A

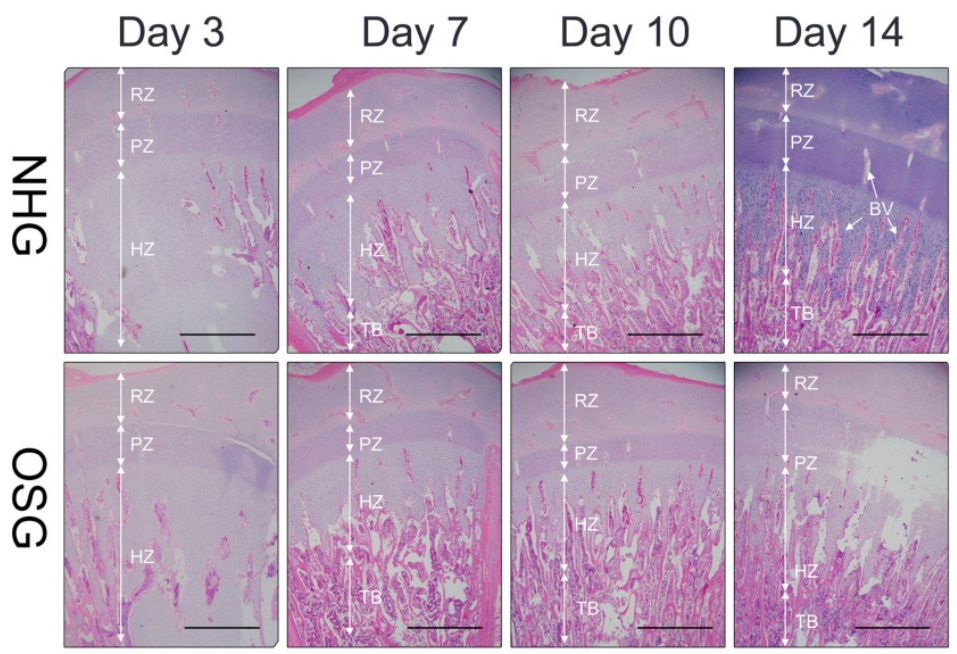

B

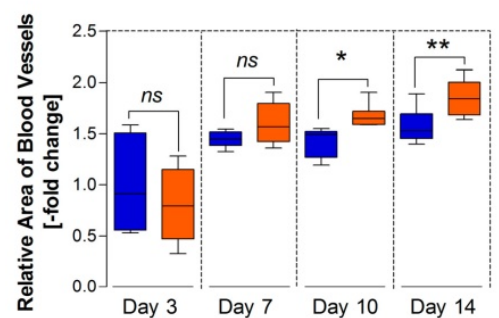

C

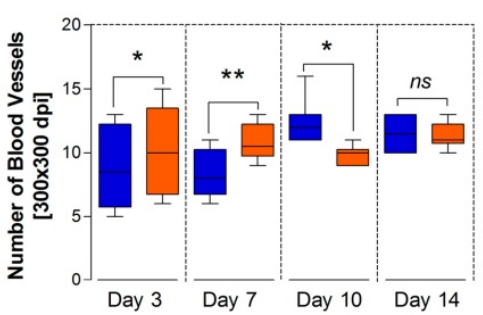

D
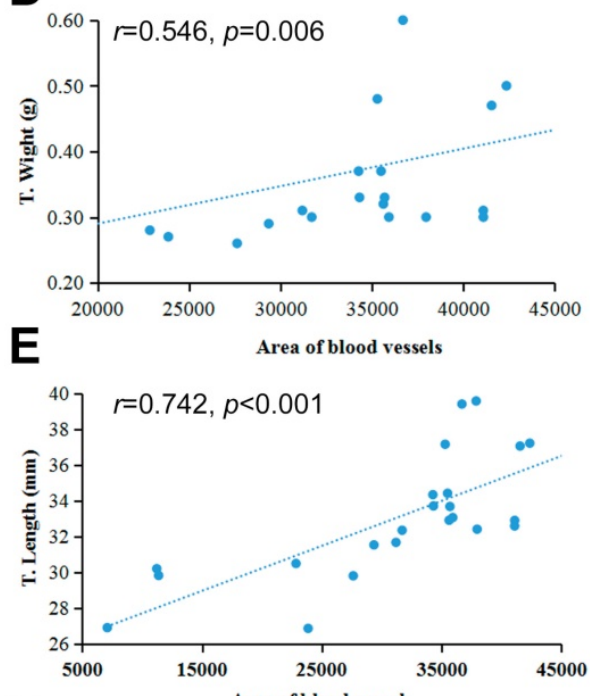

$\mathbf{F}$

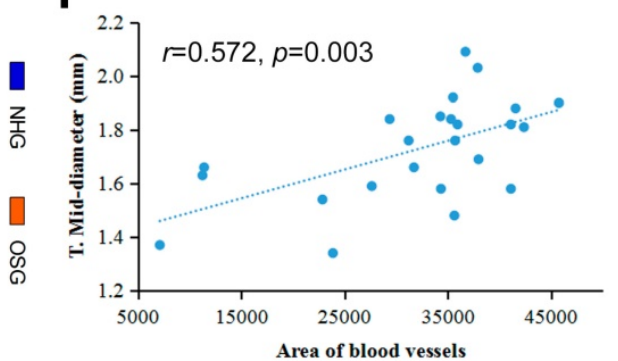

Figure 5. Histological examination of the growth plates in Tibetan chickens at high altitude. (A) Vascular distribution slightly increased in two weeks after $\mathrm{O}_{2}$ supplementation treatment compared with natural hypoxia. The arrows indicate BV (blood vessels); RZ, resting chondrocyte zone; PZ, proliferative chondrocyte zone; HZ, hypertrophic chondrocyte zone; TB, trabacular bone. Scale bar=500 $\mu \mathrm{m}$. (B-C) The relative area of BV (vs. NHG, day 3 ) and number of BV were counted with two isolated groups using Image-Pro ${ }^{\circledR}$ Plus $6.0(n=6)$. (D-F) Correlation analysis of an relative area of blood vessels $(n=6)$ and tibia parameters $(n=16)$ during the experiment with Pearson test. The data are presented as the mean \pm SD. Student's $t$ test, ${ }^{*} p<0.05$, ${ }^{* *} p<0.01(\mathbf{B}, \mathbf{C})$; ns: not significant; NHG: natural hypoxia group; OSG: oxygen supplementation group.

\section{Positive staining of antibody is enhanced in the tibial hypertrophy zone}

VEGFA is considered to be a master regulator of the angiogenesis and it may play an important role in the increased vascular distribution of the tibia hypertrophic zone [23]. Therefore, to evaluate the changes of the expression of HIF-1a and VEGFA antibody in the tibia hypertrophic zone under $\mathrm{O}_{2}$ supplementation conditions, immunohistochemistry analysis was performed. During the statistical analysis of immunohistochemical pictures, we noticed that the positive staining of the VEGFA antibody was increased during the experiment, especially on day 3 and $-14\left(p<0.001\right.$ and $p<0.001$, respectively) after $\mathrm{O}_{2}$ supplementation compared with natural hypoxic conditions as shown in Fig. 6C and D. Similarity, the positive staining of HIF-1a was also increased on day $10(p=0.005)$, however diminished on day 14 (Fig. 6A and $\mathrm{B})$. These results suggest that HIF-1a has a stimulating elevation and subsequently inhibited via $\mathrm{O}_{2}$ supplementation and elevated VEGFA is involved in the angiogenesis of the tibia.

\section{Angiogenesis related genes and proteins were up-regulated in tibia}

Although $\mathrm{O}_{2}$ supplementation could enhance vascular distribution in the hypertrophic zone of tibia linking to VEGFA antibody expression, the underlying molecular mechanism is not well understood. To explore the transcriptional and translational levels of angiogenesis-related genes in tibial growth plate of the TBC, we performed qRT-PCR and Western blotting for the HIF-1a, VEGFA and VEGFR1 using tissues obtained from the early phase tibia (day $3,-7,-10$ and -14 , respectively). As showed in Fig. 7A-C, a significant increased mRNA expression level of the VEGFA on day 7 and $-10 \quad(p=0.001$ and $p=0.022$, respectively $)$, and the VEGFR1 on day $7,-10$ and $-14(p=0.035, p=0.048$ and 
$p=0.006$, respectively) were observed in the tibial growth plate of OSG as compared to NHG. However, the HIF-1a was elevated on day $3(p=0.004)$, and

A
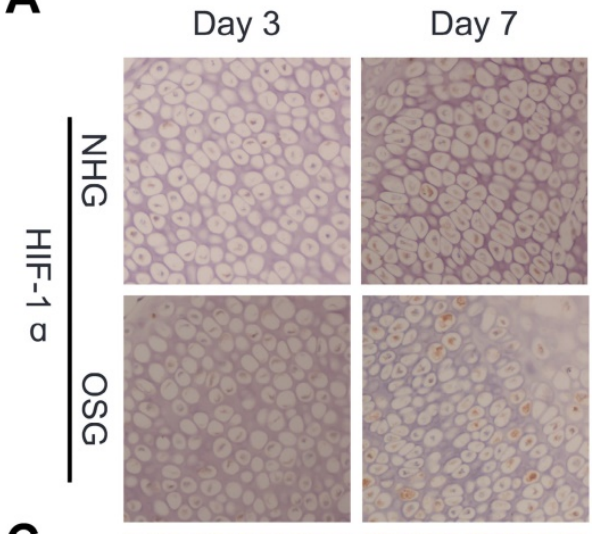

Day 10

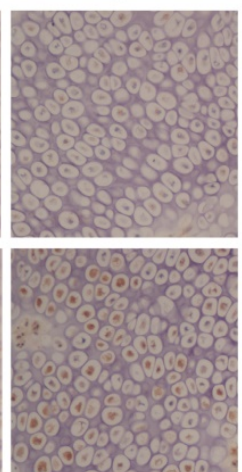

C
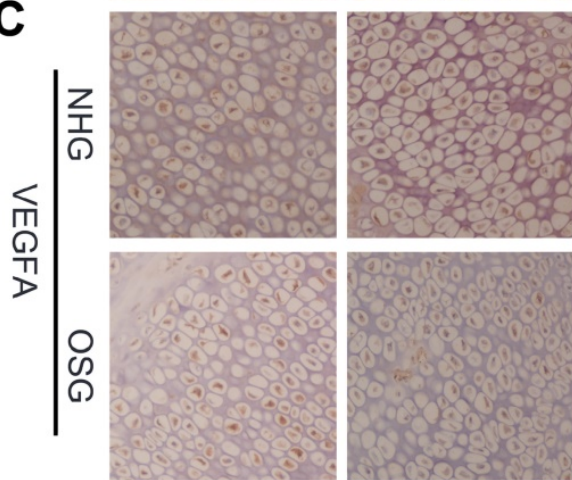

subsequently significantly decreased on day 14 $(p=0.003)$. Additionally, HIF-1a expression has a clearly downtrend during the experiment.

B

Day 14

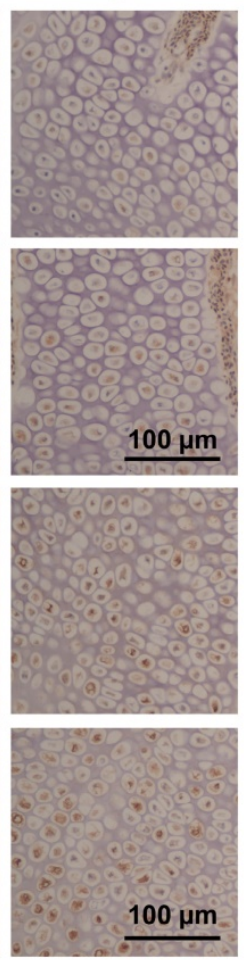

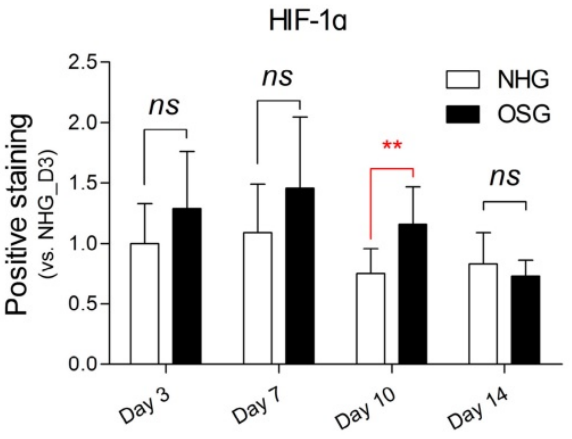

D

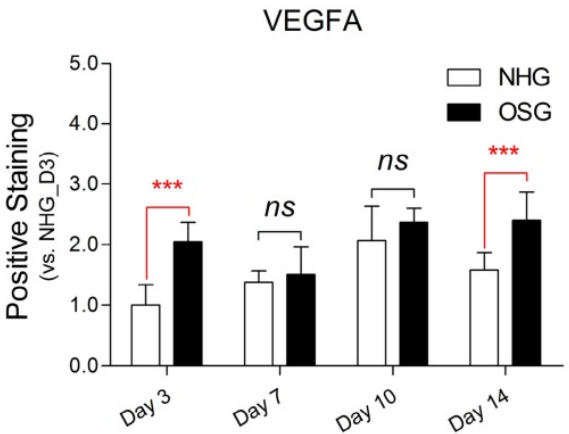

Figure 6. $\mathrm{O}_{2}$ supplementation increased VEGFA antibody in the tibial hypertrophic zone. (A-D) The number of the immunohistochemical staining and analysis of the results were analyzed using Image-Pro ${ }^{\circledR}$ Plus 6.0 and SPSS 17.0, respectively. Scale bar $=100 \mu \mathrm{m}$. The data are expressed as the mean \pm SD. Student's $t$ test, ${ }^{* * *}$ p<0.001, n=9; ns: not significant; NHG: natural hypoxia group; OSG: oxygen supplementation group.

Furthermore, Western blotting identified that $\mathrm{O}_{2}$ supplementation obviously increased levels of the HIF-1a protein, VEGFA protein, and VEGFR1 protein in tibia, especially on day 7 and -10 , as compared to the NHG (Fig. 7D). In addition, to further confirm the changes in the serum protein levels of the HIF-1a, VEGFA, VEGFR2 and IL-8. ELISA was performed to compare the serum protein concentrations of the OSG and NHG. In the OSG, the serum protein concentration of HIF-1a was slightly enhanced on day $7(p=0.126)$, subsequently significant decreased on day $14(p=0.002)$, that of VEGFA was significantly increased during the experimental period $(p<0.001)$, that of VEGFR2 had a similar change with HIF-1a on day $7(p=0.053)$ and day $14(p=0.009)$, and that of IL-8 was markedly enhanced on day $10 \quad(p<0.001)$ compared to the NHG, as shown in Fig. 7E-H. Collectively, these results demonstrated that the expression levels of VEGFA and VEGFR1 are higher under $\mathrm{O}_{2}$ supplementation than those under natural hypxia conditions. It suggests that $\mathrm{O}_{2}$ supplementation can promote VEGFA and VEGF receptors up-regulation accompanied by HIF-1a expression enhancing vascular formation in the tibia.

\section{Direct correlation between area of blood vessels and the expression of genes in tibia}

The programme of angiogenesis is regulated by a complex molecular mechanism. We next determined whether the expressions of VEGFA and VEGFR1 are corrected with angiogenesis in tibia contributing to promote tibia development. Analysis results showed that the expressions of VEGFA and VEGFR1 in tibial growth plate were positively correlated to the area of blood vessels in the corresponding hypertrophic zone ( $r=0.450, p=0.027$ and $r=0.424, p=0.039$, respectively) (Fig. 7I and J). Thus, these results strongly suggested that the increase of vascular distribution in tibia hypertrophic zone is highly correlated with the up-regulation of angiogenesis-related genes (including VEGFA and VEGFR1) under $\mathrm{O}_{2}$ supplementation conditions.

\section{Discussion}

In the present study, we demonstrated for the first time that in the hypoxic environment, $\mathrm{O}_{2}$ supplementation increased the survival rate and enhanced the growth of TBCs by increasing the BW, 
ADFI and ADG and decreasing FCR. Moreover, $\mathrm{O}_{2}$ supplementation could promote the development of the tibia by elevating the $\mathrm{T}$. weight, $\mathrm{T}$. length and $\mathrm{T}$. mid-diameter to ameliorate body size of TBCs, which are also directly associated with the weight gain. More importantly, we noticed that vascular distribution and angiogenesis-related VEGFA antibodies in tibia were enhanced after $\mathrm{O}_{2}$ supplementation treatment. As the blood vessels are essential for the transport of oxygen and nutrients to tissues, therefore $\mathrm{O}_{2}$ supplementation helped to promote bone development and repair [32-34]. The following evidence demonstrates that significant remediation of angiogenesis, resulting from increased expression of VEGFA and its receptors (mediated by the HIF-1a expression), also led to improving bone development in TBCs (Fig. 8). In light of these findings, our study identified the protective role of $\mathrm{O}_{2}$ supplementation in juvenile TBCs that promote tibial angiogenesis and contribute to bone development against hypoxia-induced suppression.
A

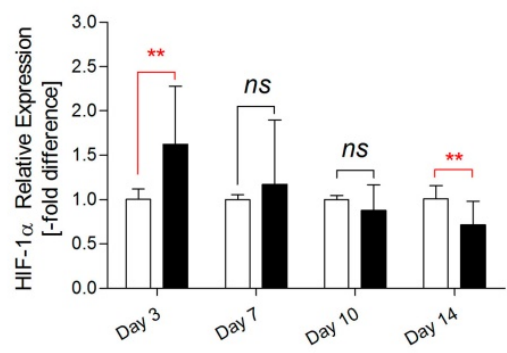

D
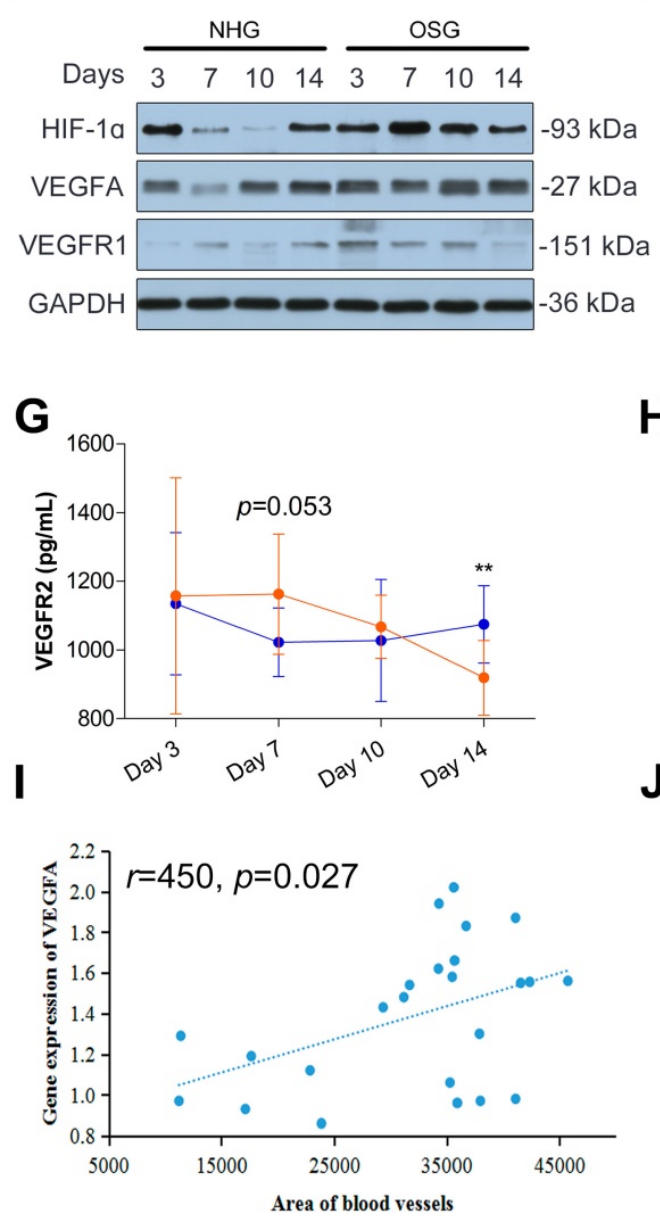

B

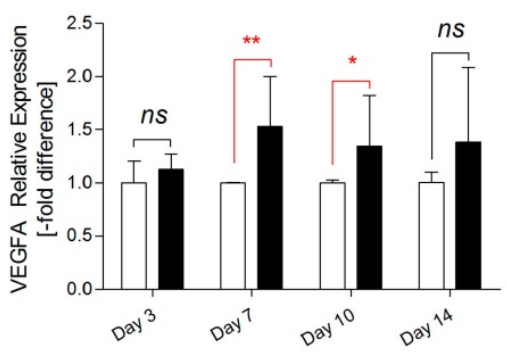

E

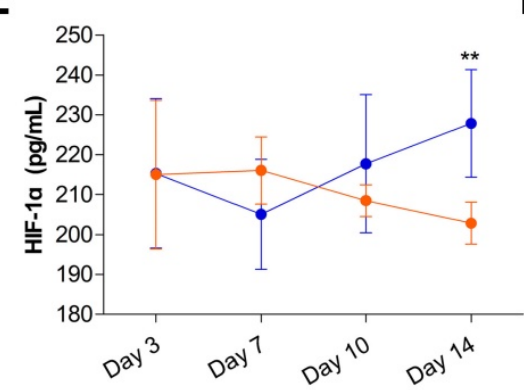

$\mathbf{F}$

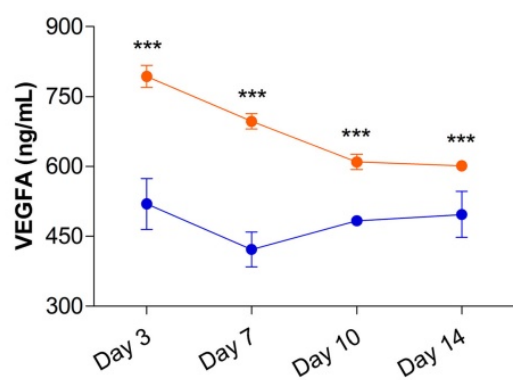

\section{H}
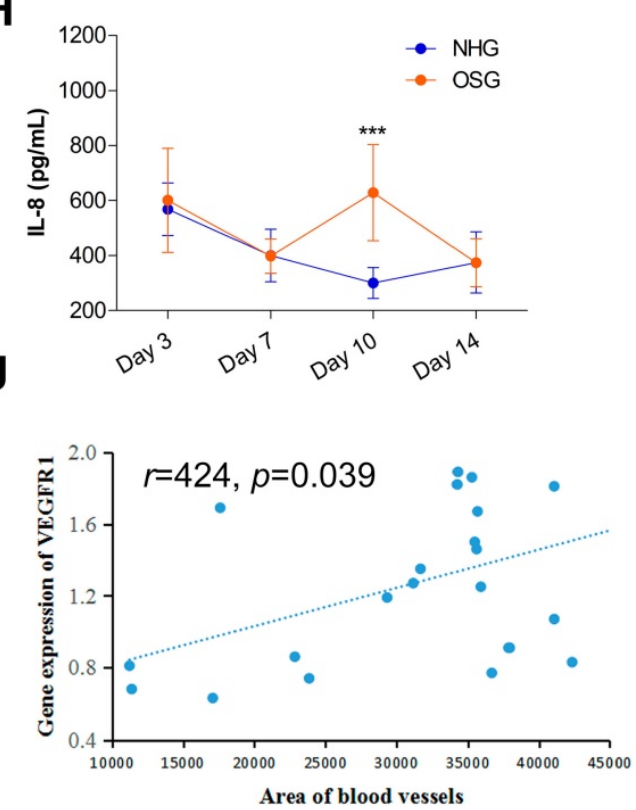

Figure 7: $\mathbf{O}_{2}$ supplemetation elevated vascular related gene expressions in Tibetan chickens. (A-D) Protein expression levels of the HIF-1a, VEGFA, and VEGFR 1 were determined by Western blotting, mRNA expression levels of the HIF-1 a, VEGFA, and VEGFRI as determined by qRT-PCR. mRNA levels from the control group were normalized to a value of 1. GAPDH was used as the loading control. The results are representative of at least three independent experiments run in triplicate and expressed as the mean \pm SEM $(n=3)$. $(\mathbf{E}-\mathbf{H})$ The serum protein concentrations of HIF-1a, VEGFA, VEGFR2, and IL-8 were measured using an ELISA kit 
$(n=3) .(I, J)$ A positive correlation in VEGFA and VEGFR I were found with Pearson's test between the average blood vessel area ( $n=6)$ and average gene expression level in the tibia $(n=3)$ during the experiment. Student's $t$ test, ${ }^{*} p<0.05,{ }^{* *} p<0.01,{ }^{* * *} p<0.001(\mathbf{A}-\mathbf{C}$ and E-H); ns: not significant; NHG: natural hypoxia group; OSG: oxygen supplementation group.

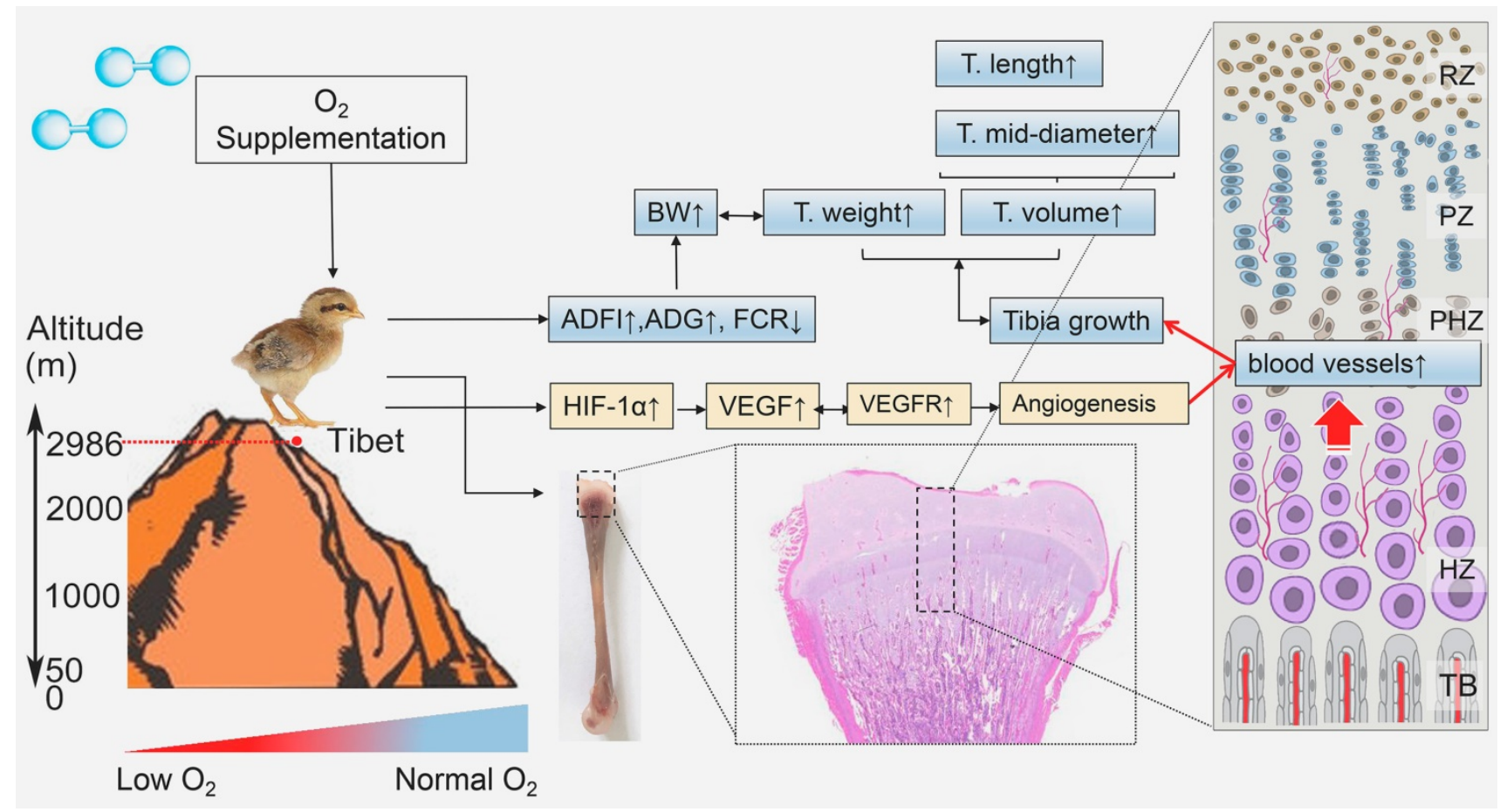

Figure 8. Model of $\mathrm{O}_{2}$ supplementation plays an ameliorative role in bone development by promoting angiogensis. $\mathrm{O}_{2}$ supplementation (relative hyperoxic condition) could enhance the growth of Tibetan chickens and promote bone development by up-regulating angiogenesis related genes expression against high-altitude hypoxia in body suppression. ADFI: average daily feed intake; ADG: average daily weight gain; FCR: Feed conversion ratio; BW: body weight; T.weight: Tibia weight; T. length: tibia length; T. mid-diameter: tibia mid-diameter.

Previous studies have shown that the growth of TBCs with low weight gain was suppressed in a hypoxic environment [3]. Similar results were also observed in rats that hypoxia reduced the food intake of rats resulting in weight loss [6, 7]. Therefore, sufficient oxygen in the air is very important for the normal growth and development of animals. Experimental studies found that $\mathrm{O}_{2}$ supplementation has some beneficial effects including neuroprotective [35], ischemic tissue [36], angiogenesis and wound healing [12, 13]. However, whether $\mathrm{O}_{2}$ supplementation has a promoting effect on the growth of TBCs or ameliorating effect on hypoxia-suppressed weight gain is unclear. In the present study, our data demonstrated that following $\mathrm{O}_{2}$ supplementation, the body weight of TBCs was increased significantly and its production performance was also elevated consistently, which may be due to increased concentration of oxygen in the blood to promote metabolism. Such results, in concert with other studies, suggest a relationship between $\mathrm{O}_{2}$ supplementation and the growth of TBCs. In addition, we also found that the growth of TBCs have a strongly positive correlation with the bone development under $\mathrm{O}_{2}$ supplementation conditions. Therefore, we speculated the possibility that $\mathrm{O}_{2}$ supplementation accelerates the growth and development of bone contributing to enhancement of growth ability of TBCs living in a hypoxic environment.

From the results of our current study, we observed that tibial vascular distribution in the hypertrophic zone was enhanced under $\mathrm{O}_{2}$ supplementation conditions. Interestingly, these findings have a strongly positive correlation between vascular distribution and tibial mass and tibial volume. It is well known that the growth and development of bone depends on the nutritional support of the blood [16]. Similar results were also reported previously that blood vessels are important in bone formation, as they are key contributors to the process of osteogenesis during bone development and repair [32, 34]. Moreover, once decreased blood supply to bone tissue ultimately leads to reduction in bone weight [37]. Similarly, $\mathrm{Li}$ et al. indicated that increasing angiogenesis and osteogenesis could prevent bone loss in rats that these findings are associated with the activation of HIF-1a signaling pathway [34]. This prompted us to investigate whether $\mathrm{O}_{2}$ supplementation enhances bone mass and bone volume against hypoxia-induced bone suppression. Our data showed $\mathrm{O}_{2}$ supplementation 
not only increased tibia weight but also enhanced tibia volume including tibia length and tibia mid-diameter. These findings strongly suggested that $\mathrm{O}_{2}$ supplementation ameliorates the growth and development of the tibia against hypoxia-induced bone suppression by angiogenesis in the tibial growth plate.

The growth and development of bone depend on sufficient and timely oxygen and nutrient supply resulting from neoangiogenesis [32, 33]. In other words, angiogenesis is critical for bone growth. VEGFA and its receptors are best known as a key regulator for angiogenesis by promoting the proliferation, the survival and the migration of endothelial cells [37-40]. Previous studies have also shown that the regulation of blood vessel growth to match the needs of the tissue depends on the control of VEGF production through modulates in the stability of its mRNA and in its rate of transcription [41, 42]. Similarity, Li et al. also reported that the increased VEGF expression led to significant remediation of angiogenesis in order to improve bone development in ovariectomized rats [34]. These evidences collectively suggest that VEGF expression is important for angiogenesis to promote bone growth.

In addition, HIF-1a pathway is the central regulator of the adaptive response to different oxygen levels $[19,43,44]$. It not only directly regulates angiogenesis, but also promotes the expression of angiogenesis-related genes contributing to indirectly modulate the formation of blood vessels [33, 45, 46]. Stegen et al. reported that the activation of the HIF-1a signaling pathway stimulates blood vessel growth for the establishment of a vascular system and bone formation in cell-based constructs, which was manifestly reduced after HIF-1a silencing [33]. Furthermore, HIF-1a is also necessary for increased VEGF production to mediate the angiogenic response during bone repair $[47,48]$. As we all know, many studies have reported the effects of hypoxia on the expression of HIF-1a, especially in tumors [43, 49-51]. However, whether $\mathrm{O}_{2}$ supplementation also contributes to the expression of HIF-1a in Tibetan chickens is unclear. In the present study, our data demonstrated that the expression levels of VEGFA and VEGFR1 significantly up-regulated during the experiment, along with HIF-1a stimulating increase under $\mathrm{O}_{2}$ supplementation conditions. Consistent with our results, other authors have also shown that the expressions of HIF-1a, VEGF and VEGFR in $\mathrm{LNCaP}$ tumors in hyperoxic condition were significantly higher than those of normoxic condition [19]. Interestingly, above changes are highly correlated with the increase of vascular distribution in tibia hypertrophic zone under $\mathrm{O}_{2}$ supplementation conditions. Collectively, these data strongly suggested that activated VEGFA and its receptor through proangiogeneic factor HIF-1a are directly or indirectly required for the vascular distribution to meliorate tibia development of TBCs.

In summary, we have identified that $\mathrm{O}_{2}$ supplementation as a protective role can meliorate tibial angiogenesis against hypoxia-induced bone growth suppression by activating VEGFA signaling pathway. Moreover, it also increased the survival rate and meliorated growth of TBCs. Further studies are warranted to elucidate that how HIF-1a activatation is involved in down streaming angiogenesis-related genes, which are regulated under $\mathrm{O}_{2}$ supplementation conditions.

\section{Abbreviations}

TBCs: Tibetan chickens; $\mathrm{O}_{2}$ : oxygen; VEGF: vascular endothelial growth factor; HIF: hypoxia inducible factor; IL: interleukin; OSG: oxygen supplementation group; NHG: natural hypoxia group; ADG: average daily weight gain; ADFI: average daily feed intake; FCR: feed conversion ratio.

\section{Acknowledgments}

The study was supported by the National Key R \& D Program of China (Project No. 2017YFD0502200) and the National Natural Science Foundation of China (No. 31460682). In addition, the authors sincerely acknowledge and thank the Tibet Agriculture and Animal Husbandry College for permission to conduct the experiments and for providing the experimental site.

\section{Author contributions}

JKL and SCH conceived and designed the experiments. $\mathrm{SCH}$ drafted the manuscript. $\mathrm{SCH}$ and XLT contributed statistical analysis. SCH, XLT, LHZ, MUR, MW and LW performed the experiments. $\mathrm{SCH}$, MUR and SJY analyzed the results. All authors contributed to critical review of manuscript.

\section{Competing Interests}

The authors have declared that no competing interest exists.

\section{References}

1. Liu C, Zhang LF, Li N. The specific expression pattern of globin mrnas in tibetan chicken during late embryonic stage under hypoxia. Comp Biochem Physiol A Mol Integr Physiol. 2013; 164: 638-644.

2. Su Y, Li D, Gaur U, Wang Y, Wu N, Chen B, et al. Genetic diversity of bitter taste receptor gene family in Sichuan domestic and Tibetan chicken populations. J Genet. 2016; 95:675-681.

3. Huang S, Zhang L, Rehman MU, Iqbal MK, Lan Y, Mehmood K, et al. High altitude hypoxia as a factor that promotes tibial growth plate development in broiler chickens. Plos One. 2017; 12: e0173698.

4. Mees G, Dierckx R, Vangestel C, Wiele CVD. Molecular imaging of hypoxia with radiolabelled agents. Eur J Nucl Med Mol Imaging. 2009; 36:1674-1686. 
5. Semenza G. Hypoxia-Inducible Factors in Physiology and Medicine. Cell. 2012;148: 399-408.

6. González-Muniesa P, Quintero P, Andrés JD, Martínez JA. Hypoxia: a consequence of obesity and also a tool to treat excessive weight loss. Sleep Breath. 2015; 19: 7-8.

7. Liu XW, Yin J, Ma QS, Qi CC, Mu JY, Zhang L, Gao LP, Jing YH. Role of Arcuate Nucleus in the Regulation of Feeding Behavior in the Process of Altitude Acclimatization in Rats. High Alt Med Biol. May 2017, ahead of print. doi:10.1089/ham.2016.0141

8. Moore DP, Weston AR, Hughes JM, Oakley CM, Cleland JG. Effects of increased inspired oxygen concentrations on exercise performance in chronic heart failure. Lancet. 1992; 339: 850-853.

9. O'Donnell DE, D'Arsigny C, Webb KA. Effects of hyperoxia on ventilatory limitation during exercise in advanced chronic obstructive pulmonary disease. Am J Respir Crit Care Med. 2001; 163: 892-898.

10. André-Lévigne D, Modarressi A, Pignel R, Bochaton-Piallat M, Pittet-Cuénod B. Hyperbaric oxygen therapy promotes wound repair in ischemic and hyperglycemic conditions, increasing tissue perfusion and collagen deposition. Wound Repair Regen. 2016; 24: 954-965.

11. Brinkmann C, Metten A, Scriba P, Tagarakis CV, Wahl P, Latsch J, et al. Hypoxia and hyperoxia affect serum angiogenic regulators in $\mathrm{t} 2 \mathrm{dm}$ men during cycling. Int J Sports Med. 2017; 38: 92-98.

12. Daugherty WP, Levasseur JE, Sun D, Rockswold GL, Bullock MR. Effects of hyperbaric oxygen therapy on cerebral oxygenation and mitochondrial function following moderate lateral fluid-percussion injury in rats. J Neurosurgery. 2004; 101: 499-504.

13. González-Muniesa P, Garcia-Gerique L, Quintero P, Arriaza S, Lopez-Pascual A, Martinez JA. Effects of hyperoxia on oxygen-related inflammation with a focus on obesity. Oxid Med and Cell Longev. 2016; 2016: 1-11.

14. S. Sgavioli DFD, Castiblanco DM, Praes MF, Andradegarcia GM, Santos ET, et al. Silicon in broiler drinking water promotes bone development in broiler chickens. Br Poult Sci. 2016; 57: 693-698.

15. Sheikh AY, Gibson JJ, Rollins MD, Hopf HW, Hussain Z, Hunt TK. Effect of hyperoxia on vascular endothelial growth factor levels in a wound model. Arch Surg. 2000; 135: 1293-1297.

16. Filipowska J, Tomaszewski KA, Lukasz NiedZwiedzki, Walocha JA, Niedzwiedzki T. The role of vasculature in bone development, regeneration and proper systemic functioning. Angiogenesis. 2017; 1-12. doi:10.1007/s10456 -017-9541-1.

17. Marx RE, Ehler WJ, Tayapongsak P, Pierce LW. Relationship of oxygen dose to angiogenesis induction in irradiated tissue. Am J Surg. 1990; 160: 519-524.

18. Hopf HW, Angeles AP, Constant JS, Feng JJ, Rollins MD, Zamirul HM, et al. Hyperoxia and angiogenesis. Wound Repair Regen. 2005; 13: 558-564.

19. Terraneo L, Virgili E, Caretti A, Bianciardi P, Samaja M. In vivo hyperoxia induces hypoxia-inducible factor-1a overexpression in lncap tumors without affecting the tumor growth rate. Int J Biochem Cell Biol. 2014; 51: 65-74.

20. Ozaki NK, Beharry KD, Nishihara KC., Akmal Y, Ang JG, Sheikh R, et al. Regulation of retinal vascular endothelial growth factor and receptors in rabbits exposed to hyperoxia. Invest Ophth Vis Sci. 2002; 43: 1546-1557.

21. Hafner C, Wu J, Tiboldi A, Hess M, Mitulovic G, Kaun C, et al. Hyperoxia induces inflammation and cytotoxicity in human adult cardiac myocytes. Shock. 2017; 47: 436-444.

22. Giddabasappa A, Eswaraka JR, Barrett CM, Bauler MN, Wu Z, Yepuru M et al. $\beta$-lgnd2, an er $\beta$ selective agonist, inhibits pathologic retinal neovascularization. Invest Ophth Vis Sci. 2012; 53: 5066-5075.

23. Cecilia O, Martindale J L, Marialaura A, et al. Induction of VEGFA mRNA translation by CoCl2 mediated by HuR[J]. RNA Biol. 2015, 12(10):1121-1130.

24. Kendall AC, Whatmore JL, Harries LW, Winyard PG, Smerdon GR, Eggleton $P$. Changes in inflammatory gene expression induced by hyperbaric oxygen treatment in human endothelial cells under chronic wound conditions. Exp Cell Res. 2011; 318: 207-216.

25. Herzog A, Genin O, Hasdai A, Shinder D, Pines M. Hsp90 and angiogenesis in bone disorders--lessons from the avian growth plate. Am J Physiol Regul Integr Comp Physiol. 2011; 301: R140-147.

26. Nabi F, Shahzad M, Liu J, Li K, Han Z, Zhang D, et al. Hsp90 inhibitor celastrol reinstates growth plate angiogenesis in thiram-induced tibial dyschondroplasia. Avian Pathol. 2016; 45: 187-193.

27. Rath NC, Huff WE, Balog JM, Huff GR. Comparative efficacy of different dithiocarbamates to induce tibial dyschondroplasia in poultry. Poult Sci. 2004; 83: 266-274.

28. Shahzad M, Gao J, Qin P, Liu J, Wang Z, Zhang D, et al. Expression of genes encoding matrilin-3 and cyclin-i during the impairment and recovery of chicken growth plate in tibial dyschondroplasia. Avian Dis. 2014; 58: 468-473.

29. Guo J, Lou W, Yuan JI, Zhang S. Effect of ccr7, cxcr4 and vegf-c on the lymph node metastasis of human pancreatic ductal adenocarcinoma. Oncol Lett. 2013; 5: 1572-1578.

30. Huang S, Rehman MU, Lan Y, Qiu G, Zhang H, Iqbal MK, et al. Tibial dyschondroplasia is highly associated with suppression of tibial angiogenesis through regulating the hif-1/vegf/vegfr signaling pathway in chickens. Sci Rep-UK. 2017; 7: 9089.

31. Maeda S, Shinchi H, Kurahara H, Mataki Y, Maemura K, Sato M, et al. Cd133 expression is correlated with lymph node metastasis and vascular endothelial growth factor-c expression in pancreatic cancer. Brit J Cancer. 2008; 98: 1389-1397.
32. Carano RA, Filvaroff EH. Angiogenesis and bone repair. Drug Discov Today. 2003; 8: 980989.

33. Stegen S, Deprez S. Eelen G, Torrekens S, Looveren RV, Goveia J, et al. Adequate hypoxia inducible factor $1 a$ signaling is indispensable for bone regeneration. Bone. 2016; 87: 176-186.

34. Li L, Qu Y, Jin X, Guo XQ, Wang Y, Qi L, Yang J, Zhang P, Li LZ. Protective effect of salidroside against bone loss via hypoxia-inducible factor-1a pathway-induced angiogenesis. Sci Rep-UK. 2016; 6:32131.

35. Yang ZS, Mu J. Co-administration of tissue plasminogen activator and hyperbaric oxygen in ischemic stroke: a continued promise for neuroprotection. Medical Gas Research. 2017; 7:68-73.

36. Shin HK, Oka F, Kim JH, Atochin D, Huang PL, Ayata C. Endothelial dysfunction abrogates the efficacy of normobaric hyperoxia in stroke. J Neurosci. 2011; 34: 15200-15207.

37. Vogt MT, Cauley JA, Kuller LH, Nevitt MC. Bone mineral density and blood flow to the lower extremities: the study of osteoporotic fractures. J Bone Miner Res. 1997; 12: 283-289.

38. Hulse RP, Beazley-Long N, Hua J, Kennedy H, Prager J, Bevan H, et al. Regulation of alternative VEGF-A mrna splicing is a therapeutic target for analgesia. Neurobiol Dis. 2014; 71: 245-259.

39. Nesmith JE, Chappell JC, Cluceru JG, Bautch VL. Blood vessel anastomosis is spatially regulated by flt1 during angiogenesis. Development. 2017; 144: 889-896.

40. Oshikawa M, Okada K, Kaneko N, Sawamoto K, Ajioka I. Affinity-Immobilization of VEGF on Laminin Porous Sponge Enhances Angiogenesis in the Ischemic Brain. Advanced healthcare materials. Adv healthc mater. 2017; 1700183, doi: 10.1002 /adhm.201700183.

41. Hara A, Okayasu I. Cyclooxygenase-2 and inducible nitric oxide synthase expression in human astrocytic gliomas: correlation with angiogenesis and prognostic significance. Acta Neuropathol. 2004; 108: 43-48.

42. Bloor CM. Angiogenesis during exercise and training. Angiogenesis. 2005; 8: 263-271.

43. Carmeliet P, Dor Y, Herbert JM, Fukumura D, Brusselmans K, Dewerchin M et al. Role of hif-1alpha in hypoxia-mediated apoptosis, cell proliferation and tumour angiogenesis. Nature. 1998; 394:485-490.

44. Benderro GF, Tsipis CP, Sun X, Kuang Y, Lamanna JC. Increased hif-1a and hif-2a accumulation, but decreased microvascular density, in chronic hyperoxia and hypercapnia in the mouse cerebral cortex. Adv Exp Med Biol. 2013; 789:29-35.

45. Ahluwalia A, Tarnawski AS. Critical role of hypoxia sensor--hif-1a in vegf gene activation. implications for angiogenesis and tissue injury healing. Curr Med Chem. 2012: 19. 90-97.

46. Clara CA, Marie SKN, Almeida JRW, Wakamatsu A, Oba-Shinjo SM, Uno M, et al. Angiogenesis and expression of PDGF-C, VEGF, CD105 and HIF-1a in human glioblastoma. Neuropathology. 2014; 34: 343-352.

47. Komatsu DE, Hadjiargyrou M. Activation of the transcription factor hif- 1 and its target genes, vegf, ho-1, inos, during fracture repair. Bone. 2004; 34: 680-688.

48. $\mathrm{Hu} \mathrm{K}$, Olsen BR. Osteoblast-derived vegf regulates osteoblast differentiation and bone formation during bone repair. J Clin Invest. 2016; 126: 509-526.

49. Borsi E. Perrone G, Terragna C, Martello M, Dico AF, Solaini G, et al. Hypoxia inducible factor-1 alpha as a therapeutic target in multiple myeloma. Oncotarget. 2014; 5: 1779-1792.

50. Jiang Y, Zhu Y, Wang X, Gong J, Hu C, Guo B, et al. Temporal regulation of hif-1 and nf-kb in hypoxic hepatocarcinoma cells. Oncotarget. 2015; 6: 9409-9419.

51. Wang $M$, Zhao X, Zhu D, Liu T, Liang X, Liu F, Zhang Y, Dong X, Sun B. HIF-1a promoted vasculogenic mimicry formation in hepatocellular carcinoma through LOXL2 up-regulation in hypoxic tumor microenvironment. J Exp Clin Canc Res. 2017; 36: 60. 